\title{
Myxoid stroma is associated with postoperative relapse in patients with stage II colon cancer
}

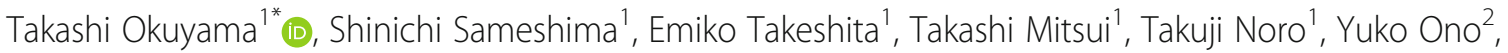

Tamaki Noie', Shinichi Ban² and Masatoshi Oya ${ }^{1}$

\begin{abstract}
Background: Fibrosis surrounding cancer cells has been shown to affect cancer cell metastatic behavior. The present study aimed to explore the utility of myxoid stroma as a predictive factor for postoperative relapse in patients with stage II colon cancer.
\end{abstract}

Methods: The present study retrospectively investigated 169 patients who underwent curative surgical resection of stage II colon cancer. The fibrotic stroma was classified according to Ueno's criteria, and the patients were divided into the myxoid (MY) group and the non-MY (NMY) group. We also recorded tumor budding (TB) and investigated the combination of MY and TB for postoperative relapse. Postoperative survival was also explored.

Results: Thirty-two (18.9\%) patients had MY. MY was significantly associated with tumor budding (TB) and postoperative relapse $(p<0.001$ and $p<0.001$, respectively). The 5-year RFS rates in MY group and NMY group were 52.1 and $94.6 \%$ $(p<0.0001)$, and the 5-year OS rates in MY group and NMY group were 74.6 and $93.3 \%(p=0.001)$. Multivariate analysis showed that both MY and TB were significant risk factors for postoperative relapse ( $p<0.001$ and $p=0.02$, respectively), and that only TB was a significant risk factor for OS $(p=0.043)$. Furthermore, compared with patients with either one of MY or TB, patients with both MY and TB had postoperative relapse more frequently (11.4\% vs. $53.8 \%)$.

Conclusions: The present study suggests that MY is a predictive marker for postoperative relapse in patients with stage II colon cancer.

Keywords: Myxoid stroma, Desmoplastic reaction, Stage II colon cancer

\section{Background}

The actual role of adjuvant chemotherapy (AC) in patients with stage II colon cancer remains unclear despite several clinical trials and meta-analyses [1-4]. However, surveillance, epidemiology, and end results analyses have shown that there are groups of patients having a higher risk of relapse than others [5]. International guidelines therefore recommend that patients with stage II colon cancer should be

\footnotetext{
* Correspondence: okuyama615@gmail.com

'Department of Surgery, Saitama Medical Center, Dokkyo Medical University, T 343-8555 2-1-50 Minami-Koshigaya, Koshigaya, Saitama, Japan Full list of author information is available at the end of the article
}

divided into a high-risk group and a low-risk group for postoperative relapse, and that AC should be considered in patients with high-risk features, but high-level evidence including molecular and genetic factors is still lacking [6-12].

Current molecular and genetic studies have indicated that tumor progression, growth, and spread are determined by the interaction between a cancer and its surrounding stromal cells $[13,14]$. The tumor stroma contains many different cells, including lymphocytes, macrophages, leukocytes, Rouget cells, vascular endothelial cells, and fibroblasts. Of these stromal cells, it is increasingly clear that active fibroblasts (cancer-associated

(c) The Author(s). 2020 Open Access This article is licensed under a Creative Commons Attribution 4.0 International License, which permits use, sharing, adaptation, distribution and reproduction in any medium or format, as long as you give appropriate credit to the original author(s) and the source, provide a link to the Creative Commons licence, and indicate if changes were made. The images or other third party material in this article are included in the article's Creative Commons licence, unless indicated otherwise in a credit line to the material. If material is not included in the article's Creative Commons licence and your intended use is not permitted by statutory regulation or exceeds the permitted use, you will need to obtain permission directly from the copyright holder. To view a copy of this licence, visit http://creativecommons.org/licenses/by/4.0/ The Creative Commons Public Domain Dedication waiver (http://creativecommons.org/publicdomain/zero/1.0/) applies to the data made available in this article, unless otherwise stated in a credit line to the data. 
fibroblasts, CAFs) are an important regulator of cancer progression, invasion, and metastasis $[15,16]$.

CAFs or myofibroblasts induce peritumoral fibrosis that may promote tumoral progression by regulating the interaction between cancer and stromal cells [17, 18]. The fibrotic stroma (i.e. desmoplastic reaction, DR) refers to the state of extracellular matrix (ECM) remodeling generated by CAFs in cancer stroma $[19,20]$. Recent reports have indicated a close relationship between the form of DR and the prognosis of patients with several solid cancers [21-23]. In the present study, the aim was to explore the relationship between myxoid stroma (one of the forms of DR) and postoperative relapse in patients with stage II colon cancer.

\section{Methods}

Resected specimens from 169 consecutive patients with stage II colon cancer at Saitama Medical Center, Dokkyo Medical University between April 2010 and March 2016 were included in this study. Patients who received neoadjuvant chemotherapy and patients with synchronous or metachronous, multiple advanced cancers were excluded. Pathological findings were classified according to the TNM classification of Malignant Tumors (8th edition) [24]. The lymph node dissection was considered sufficient when 12 or more lymph nodes had been examined pathologically [24]. This study was approved by the Ethics Committee of Saitama Medical Center, Dokkyo Medical University (No. 1762).

\section{Desmoplastic reaction and tumor budding}

DR was assessed at the advancing edge of a primary tumor with hematoxylin and eosin (H\&E) staining, and the specimens were divided according to Ueno's criteria: the myxoid stroma (MY) group and the non-myxoid stroma (NMY) group [25] (Fig. 1). Immature stroma in Ueno's criteria was defined as MY, and mature fibrosis and keloid-like stroma was defined as NMY in this study. When tumors involved the areas of myxoid changes (an amorphous stromal substance with basophilic extracellular material), the DR was recorded as MY regardless of the existence of mature stroma or keloid-like collagens. Small areas of myxoid fibrotic change were assessed according to whether these features were observed with a $40 \times \mathrm{ob}$ jective lens in areas without microscopic abscesses.

DR was evaluated by two independent observers. One of them was an experienced pathologist (YO), with no knowledge of outcomes and other clinical information, and the other was a surgeon (TO). Their inter-observer agreement was calculated using $k$-statistics. The interobserver agreement coefficient $k$ was 0.72 .

Tumor budding (TB) was evaluated with H\&E staining and defined as single cells or clusters of up to four cells at the advancing edge of colorectal cancer [26]. The evaluation of TB was performed under a $20 \times$ objective lens in the areas where TB was observed most frequently (hotspot method) [27]. TB was classified as low-grade (0-4 buds), intermediate-grade (5-9 buds), and high-grade (10 or more buds) [27, 28].

\section{Follow-up and adjuvant chemotherapy}

Postoperative surveillance including medical examinations and laboratory tests was performed every 3 months, and computed tomography (CT) of the chest, abdomen, and pelvis was performed every 6 months until 5 years after surgery. Surveillance colonoscopy was performed within 1 year after surgery and annually thereafter until no neoplastic lesions were observed. If no neoplastic lesions were detected on surveillance

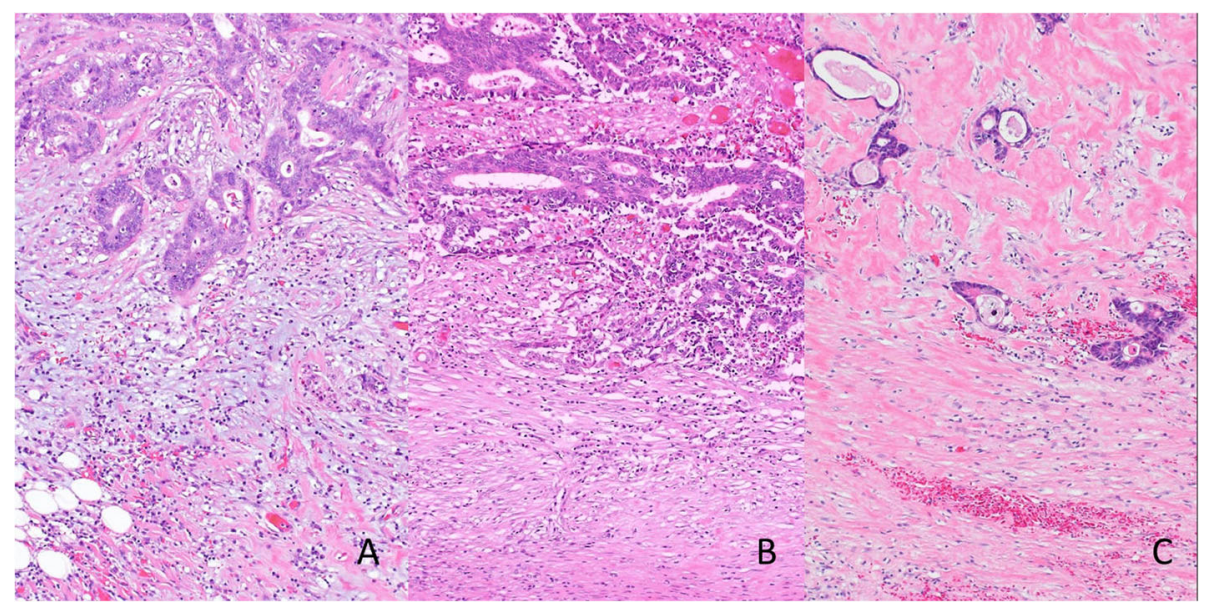

Fig. 1 a Immature type DR: amorphous and myxomatous stroma with slightly basophilic matrix. b Intermediate type DR: keloid-like, thick bundles of hypocellular collagen with bright eosinophilic hyalinization around the tumor nests. c Mature type DR: fine mature collagen fibers stratified into multiple layers. Fibrotic stroma contains neither myxomatous stroma nor keloid-like collagen $(\mathbf{a}, \mathbf{b}$, $\mathbf{c}$, hematoxylin and eosin, Magnifications $\times 100$ ). DR, desmoplastic reaction 
colonoscopy, the subsequent colonoscopy was performed 3 years later. Adjuvant chemotherapy (AC) was usually recommended to patients with high-risk features, such as T4 lesions, poor differentiation, lymphovascular or perineural invasion, < 12 lymph nodes harvested, positive margin, or bowel obstruction or perforation, for a total of 6 months using a regimen including 5fluorouracil (5-FU)-leucovorin or capecitabine (FOLFOX or CAPOX). The use and selection of the PAC regimen depended on the primary surgeon.

\section{Statistical analysis}

Associations between MY and clinicopathological findings were assessed using the two-tailed chi-squared test or Fisher's exact test. Continuous variables were assessed using the Mann-Whitney U test. RFS rate was calculated from the date of surgery to the date of diagnosis of tumor relapse. OS rate was calculated from the date of surgery to the date of death by any cause or the last follow-up visit. RFS and OS rates were calculated using the Kaplan-Meier method, and differences were evaluated using the log-rank test. Multivariate analysis was performed using the Cox proportional hazard regression model with data that trended toward significance $(P<.10)$ on univariate analysis. A two-sided $P$ value of $<.05$ was considered significant. All analyses were performed using the SPSS statistical software package, version 24. (IBM Japan Ltd., Tokyo, Japan).

\section{Results}

\section{Patients' clinical and pathological characteristics}

More than half of the patients were men (55.6\%), and the patients' average age at the time of surgery was 70.5 years (range 29-92 years). The median follow-up period of the entire patient group was 60 months. The baseline clinicopathological characteristics of the 169 patients are shown in Table 1. In this study, 32 patients (18.9\%) had MY (MY group), and 137 (71.1\%) patients did not (NMY group). The regimens of adjuvant chemotherapy in MY group and NMY group are shown in Table 2. Patients who received completely AC was 22 (13.6\%) cases (MY; 6 patients, NMY; 16 patients). Three of 22 patients who were withdrawal due to have a drug allergy, were excluded from AC group. These patients received 2-4 cycles intravenous or oral AC. Twenty-three of 169 patients developed postoperative relapses, including lung metastasis (6 patients), liver metastasis (8 patients), peritoneal dissemination (5 patients), metastasis to the paraaortic lymph nodes (3 patients), and local relapse (1 patient). Seventeen patients $(17 / 169,10.1 \%)$ died of any causes within the follow-up period, and seven of these patients $(7 / 17,41.2 \%)$ died of causes other than primary colon cancer.

\section{Relationships between myxoid stroma and} clinicopathological characteristics

The relationships between MY and clinicopathological characteristics are shown in Table 3. TB and postoperative relapse were significantly more frequent in the MY group than in the NMY group $(p<0.001$ and $p<0.001$, respectively). None of the other clinicopathological characteristics was associated with the presence of MY.

\section{Survival analyses of relapse-free survival and overall survival}

The 5-year RFS and OS rates were 87 and $89.6 \%$, respectively, for the entire group of patients in this study. The MY group had significantly lower RFS and OS rate than the NMY group $(p<0.0001$ and $p=0.001$, respectively, Figs. 2, 3). The 5-year RFS rates in MY group and NMY group were 52.1 and $94.6 \%(p<0.0001)$, and the 5-year OS rates in MY group and NMY group were 74.6 and $93.3 \%(p=0.001)$. Regarding patients who did not receive $A C$, the MY group had significantly lower RFS and OS rates than the NMY group $(p<0.001$ and $p=$ 0.028 , respectively, Figs. 4 and 5).

\section{Univariate- and multivariate analyses to identify characteristics related to relapse-free survival and overall survival}

Univariate and multivariate analyses to identify characteristics significantly related to RFS and OS rates were performed using Cox proportional hazard models (Table 4). On univariate analyses for RFS rate, TB, surgical margin, and the presence of MY were significantly associated with lower RFS rate $(p<0.001, p=0.038$ and $p=<0.001$, respectively). Regarding the OS rate, the serum CA19-9 level, deep tumor penetration, TB, positive surgical margin, and the presence of MY were significantly associated with lower OS rate in univariate analysis $(p=0.026, p=$ $0.011, p=0.001, p=0.014$ and $p=0.003$ ).

On multivariate analysis for RFS and OS rates, the presence of MY and TB were significant risk factors for RFS rate (MY: HR, 6.80; 95\% CI, 2.579-17.911; $p<$ 0.001, TB: HR, 4.11; 95\% CI, 1.301-13.002; $p=0.02$ ), and only $\mathrm{TB}$ was a significant risk factor for OS rate (HR, 1.94; 95\% CI, 1.020-3.668; $p=0.043$ ).

\section{Combination of myxoid stroma and tumor budding for postoperative relapse and survival}

The relationships of the combination of MY and TB with 5 -year RFS and OS rates are shown in Table 5. The relapse rate in patients with both $\mathrm{MY}$ and $\mathrm{TB}$ was nearly five-fold higher than with either one of MY or TB (53.8\% vs. 11.4\%). Patients with both MY and TB had a much worse 5-year RFS rate than those with either one of MY or TB $(44.2 \%$ vs. $87.7 \%, p<0.001)$. Furthermore, Cox regression analysis showed that there was a significant 
Table 1 Demographic and clinical characteristics, postoperative treatment, and outcome at baseline of participants in this study

\begin{tabular}{|c|c|c|c|}
\hline Characteristics & Number (\%) & Characteristics & Number (\%) \\
\hline Gender & & Surgical margin & \\
\hline Male & $94(55.6)$ & Negative & $163(96.4)$ \\
\hline Female & $75(44.4)$ & Positive & $6(3.6)$ \\
\hline Age (yr, average, range) & $70.5(29-92)$ & Glucose tolerance & \\
\hline Preoperative serum CEA value & & Normal & $120(71.0)$ \\
\hline$<5$ & $106(62.7)$ & Abnormal & $49(29.0)$ \\
\hline$\geq 5$ & $63(37.3)$ & Obstruction / perforation & \\
\hline Preoperative serum CA19-9 value & & Absence & $157(92.9)$ \\
\hline$<37$ & $143(84.6)$ & Presence & $12(7.1)$ \\
\hline$\geq 37$ & $26(15.4)$ & Surgical approach & \\
\hline Tumor location & & Laparotomy & $101(59.8)$ \\
\hline Right & $88(52.1)$ & Laparoscopic surgery & $68(40.2)$ \\
\hline Left & $81(47.9)$ & Examined lymph node & \\
\hline Tumor size (cm, average, range) & $5.0(1-17)$ & $\geq 12$ & $115(68.0)$ \\
\hline Differentiation & & $<12$ & $54(32.0)$ \\
\hline Well, Mod, pap & $150(88.8)$ & Postoperative adjuvant chemotherapy & \\
\hline Por, Muc, Sig & $19(11.2)$ & No & $147(86.1)$ \\
\hline pT category & & Yes & $22(13.9)$ \\
\hline pT3 & $144(85.2)$ & Postoperative relapse & $n=23$ \\
\hline pT4a & $13(7.7)$ & Lung & 6 \\
\hline pT4b & $12(7.1)$ & Liver & 8 \\
\hline Lymphatic invasion & & Peritoneum & 5 \\
\hline Absent & $104(61.5)$ & Paraaortic lymph node & 3 \\
\hline Present & $65(38.5)$ & Local relapse & 1 \\
\hline Vessel invasion & & Desmoplastic reaction & \\
\hline Absent & $71(42.0)$ & Mature stroma & $76(45.0)$ \\
\hline Present & $98(58.0)$ & Intermediate stroma & $62(36.1)$ \\
\hline Tumor budding & & Myxoid (i.e. immature) stroma & $32(18.9)$ \\
\hline Grade 1 & $106(62.7)$ & & \\
\hline Grade 2 & $43(25.4)$ & & \\
\hline Grade 3 & $20(11.9)$ & & \\
\hline
\end{tabular}

Table 2 The regimens of adjuvant chemotherapy used in patients with or without myxoid stroma

\begin{tabular}{|c|c|c|c|c|c|c|}
\hline \multicolumn{7}{|c|}{ Adjuvant Chemotherapy } \\
\hline & No & UFT/LV & CAPE & FOLFOX & XELOX & Withdrawal \\
\hline NMY & 118 & 6 & 5 & 3 & 2 & 3 \\
\hline MY & 26 & 3 & 1 & 2 & 0 & 0 \\
\hline
\end{tabular}

difference in RFS rate between patients with both MY and $\mathrm{TB}$ and those with either one of MY or TB (HR, 5.801; 95\% CI, 2.0884-16.146; $p=0.001$ ). Regarding the OS rate, there was no significant difference between patients with both MY and TB and those with either one of MY or TB on Cox regression analysis.

\section{Discussion}

The aim of the present study was to explore the utility of MY as a predictor of postoperative relapse and survival in patients with stage II colon cancer, respectively. In addition, the utility of the combination of MY and TB was similarly explored. In this study, patients with MY had more frequent postoperative relapse than those 
Table 3 The relationships between the myxoid stroma and clinicopathological characteristics analyzed using $x^{2}$ and Fisher's exact tests

\begin{tabular}{|c|c|c|c|c|c|c|c|}
\hline & \multicolumn{2}{|l|}{ Myxoid } & \multirow[b]{2}{*}{$\boldsymbol{p}$ value } & & \multicolumn{2}{|l|}{ Myxoid } & \multirow[b]{2}{*}{$\boldsymbol{p}$ value } \\
\hline & Absent (\%) & Present (\%) & & & Absent (\%) & Present (\%) & \\
\hline Gender) & & & & Lymphatic invasion & & & \\
\hline Female & $62(45)$ & $13(41)$ & 0.7 & Absent & $87(64)$ & $17(53)$ & 0.36 \\
\hline Male & $75(55)$ & $19(59)$ & & Present & $50(36)$ & $15(47)$ & \\
\hline Age & & & & Vessel invasion & & & \\
\hline$<70$ & $53(39)$ & $16(50)$ & 0.32 & Absent & $61(45)$ & $10(31)$ & 0.23 \\
\hline$\geq 70$ & $84(61)$ & $16(50)$ & & Present & $76(55)$ & $22(69)$ & \\
\hline Serum CEA value & & & & Tumor budding & & & \\
\hline$<5$ & $85(62)$ & $21(66)$ & 0.84 & Grade 1 & $100(73)$ & $6(19)$ & $<0.001$ \\
\hline$\geq 5$ & $52(38)$ & $11(34)$ & & Grade 2, 3 & $37(27)$ & $26(81)$ & \\
\hline Serum CA19-9 value & & & & Surgical margin & & & \\
\hline$<37$ & $116(85)$ & $27(84)$ & 0.26 & Negative & $133(97)$ & $31(97)$ & $1^{*}$ \\
\hline$\geq 37$ & $21(15)$ & $5(16)$ & & Positive & $4(3)$ & $1(3)$ & \\
\hline Tumor location & & & & Examined lymph node & & & \\
\hline Right & $72(53)$ & $16(50)$ & 0.85 & $<12$ & $42(31)$ & $12(38)$ & 0.53 \\
\hline Left & $65(47)$ & $16(50)$ & & $\geq 12$ & $95(69)$ & $20(62)$ & \\
\hline Tumor size $(\mathrm{cm})$ & & & & Obstruction/perforation & & & \\
\hline$<5$ & $63(46)$ & $18(56)$ & 0.33 & Absent & $128(93)$ & $29(91)$ & $0.7^{*}$ \\
\hline$\geq 5$ & $74(54)$ & $14(44)$ & & Present & $9(7)$ & $3(9)$ & \\
\hline Differentiation & & & & Glucose tolerance & & & \\
\hline Well, moderately, pap & $121(88)$ & $29(91)$ & $1^{*}$ & Normal & $95(69)$ & $25(78)$ & 0.39 \\
\hline Por, Muc, Sig & $16(12)$ & $3(9)$ & & Abnormality & $42(31)$ & $7(22)$ & \\
\hline Tumor depth & & & & Tumor relapse & & & \\
\hline pT3 & $118(86)$ & $26(81)$ & 0.58 & Absent & $129(94)$ & $17(53)$ & $<0.001$ \\
\hline pT4 & $19(14)$ & $6(19)$ & & Present & $8(6)$ & $15(47)$ & \\
\hline
\end{tabular}

*Fisher's exact tests

without MY. Furthermore, Kaplan-Meier analyses showed that patients with MY had significantly worse RFS and OS rates than those without MY, and multivariate analysis demonstrated that MY was an independent predictor of postoperative relapse in patients with stage II colon cancer. On the analysis for the combination of MY and TB, patients with both MY and TB had a significant worse 5-year RFS rate than those with either one of MY or TB. These results suggest a close relationship between MY and cancer cell metastatic behavior.

DR classified by the type of fibrotic stroma is simply detected by routine H\&E staining. This inexpensive pathological feature has been reported as a useful predictor for metastasis and survival in several solid cancers, including cutaneous cancer, breast cancer, lung cancer, pancreatic cancer, and colorectal cancer $[21,29-32]$. In colorectal cancer, although the amount of fibrosis was evaluated as an index of the stromal reaction first, Ueno et al. recently have proposed categorizing it into three types by the fibrotic responses of cancer stroma, and they reported that their classification was useful for predicting the prognosis of patients with colorectal cancer [32-34].

Recent approaches using molecular and genetic methods may offer predictive information for relapse and survival in patients with stage II colon cancer in addition to the routine pathological examination $[9$, 10]. Microsatellite instability (MSI) due to mutation or modification of mismatch repair (MMR) is mainly detected in Lynch syndrome, which is an autosomal dominant cancer syndrome associated with an increased risk of colorectal cancer and other extracolonic malignancies, including endometrial cancer, stomach, small bowel, and ovarian cancers [35, 36]. In stages II/III colorectal cancer, it is generally recognized the biological difference in tumors with MMR states [9, 10, 37]. Hutchins et al. demonstrated that 


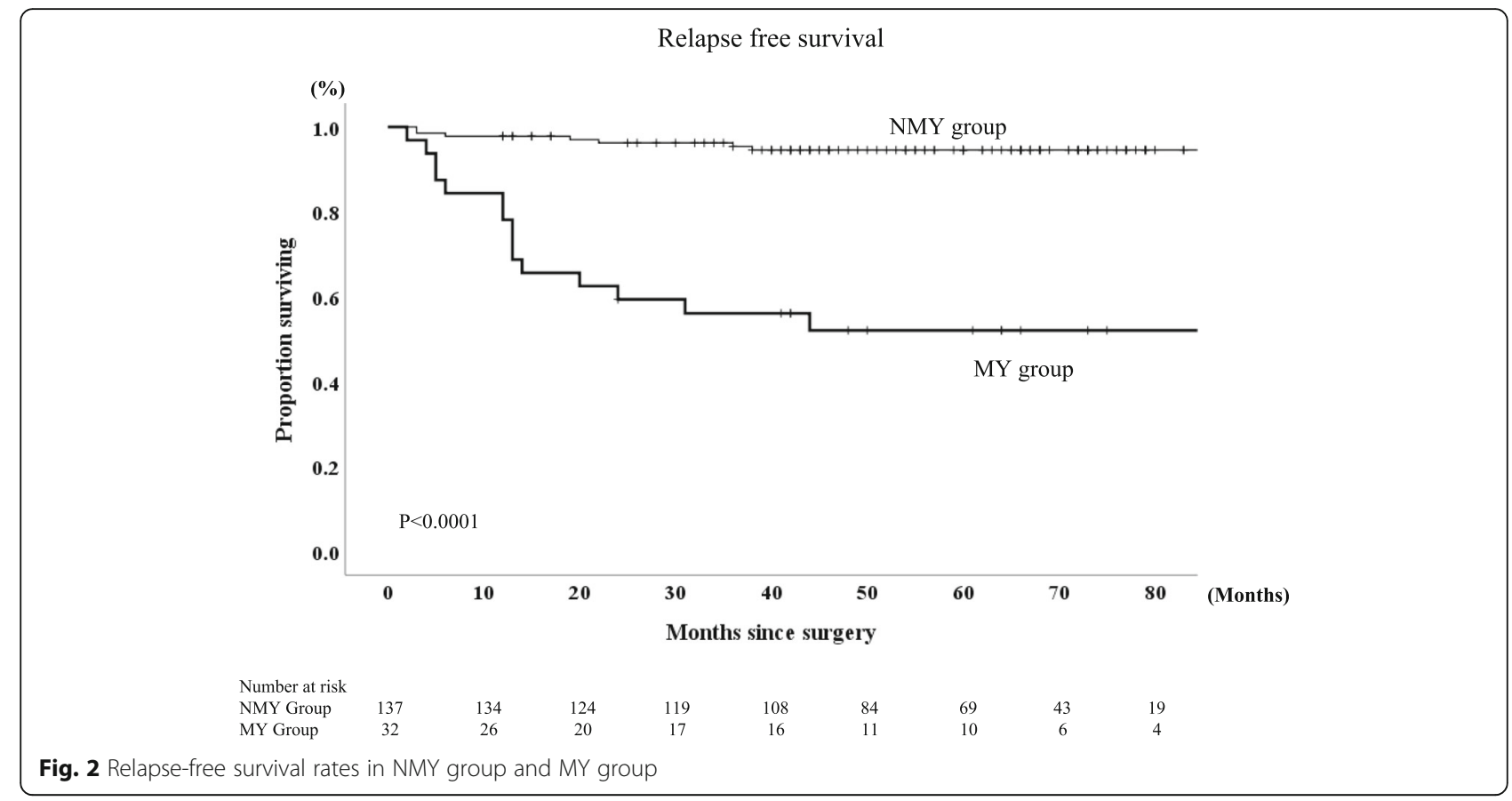

patients with dMMR had significantly lower relapse than that with pMMR [38]. On the other hand, Ribic et al. and Sargent et al. reported that there was no benefit from FU based AC in stage II/III patients with dMMR [37, 39]. In addition, Gavin et al. showed MMR states were not predictive for oxaliplatin benefit [10]. Although MSI or the MMR test need immunohistochemistry or expensive gene analyses, clinical evidence supporting their use is still insufficient.

Among cells of the stromal component, fibroblasts have been termed cancer-associated fibroblasts (CAFs) and are important promotors of tumor progression and metastasis [40]. CAFs can induce dedifferentiation by

Overall survival

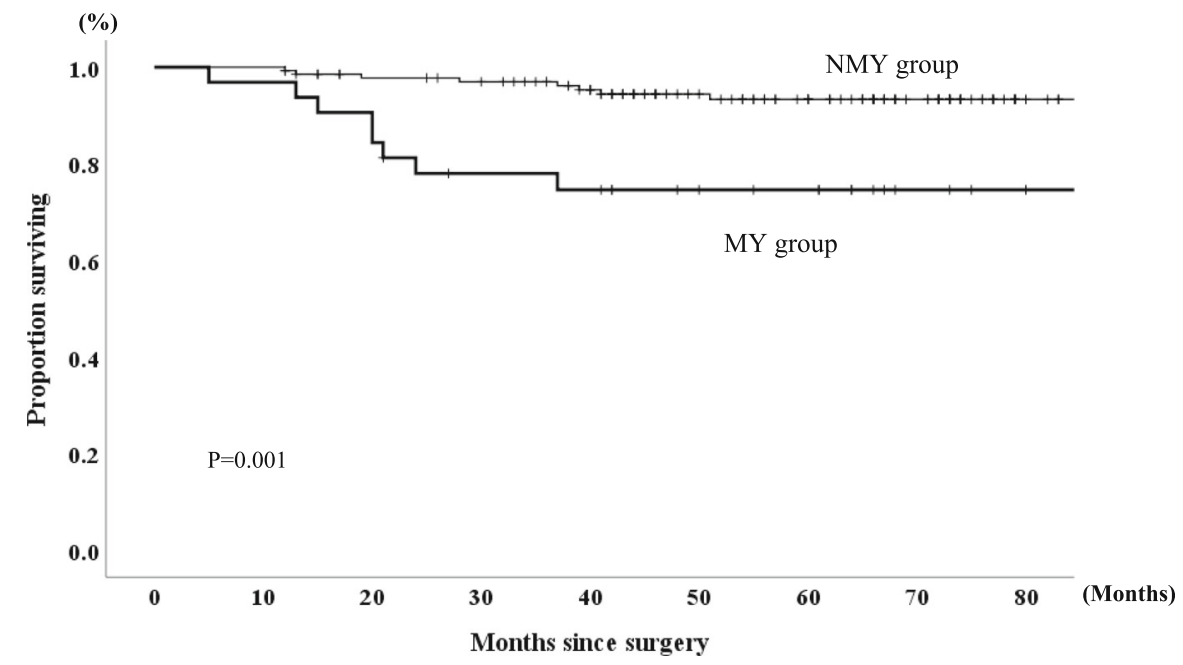

Number of at risk $\begin{array}{lccccccccc}\text { NMY Group } & 137 & 136 & 127 & 123 & 111 & 86 & 71 & 45 & 19 \\ \text { MY Group } & 32 & 30 & 28 & 22 & 21 & 17 & 15 & 9 & 6\end{array}$

Fig. 3 Overall survival rates in NMY group and MY group 
Relapse free survival (AC-)

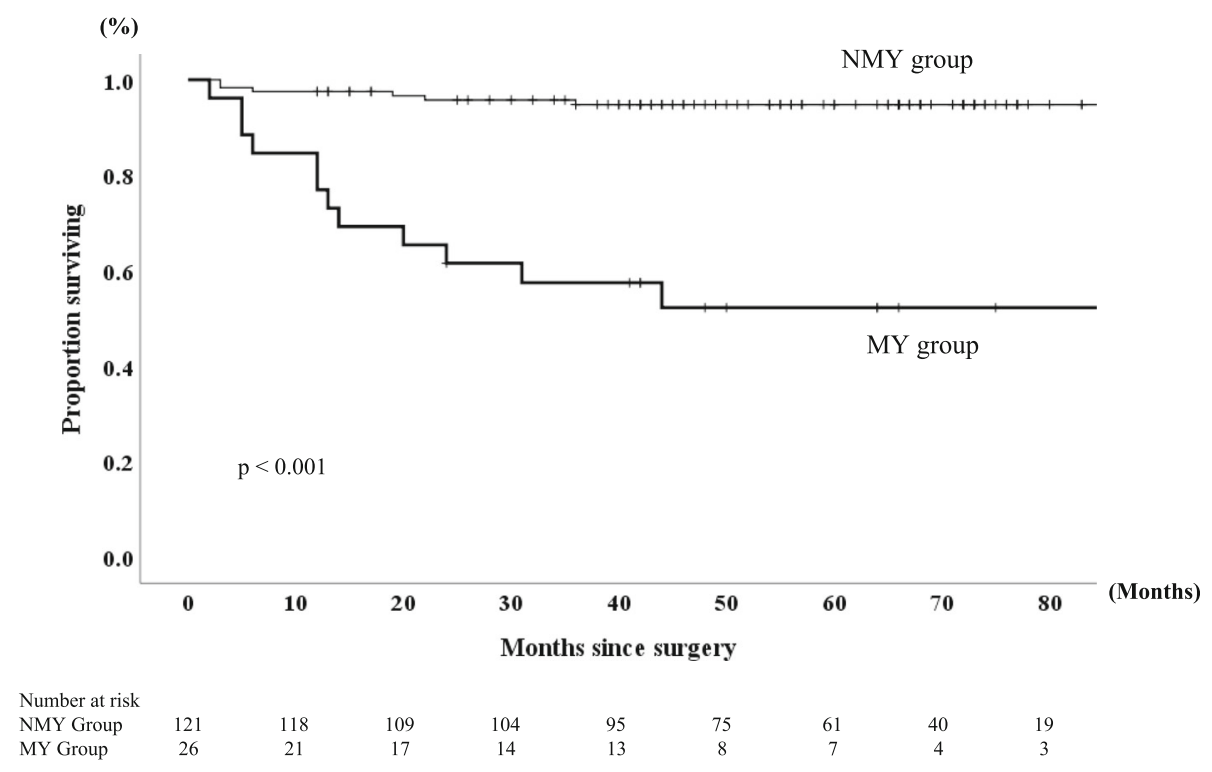

Fig. 4 Relapse-free survival rates in NMY group and MY group without adjuvant chemotherapy

extracellular matrix (ECM) remodeling and desmoplasia by increasing the deposition of ECM [20, 41]. In several reports, single or small clusters of cancer cells (TB) have been frequently observed at MY areas [25, 29], and TB was associated with DR in the present study. These results suggest that CAFs may have a critical role in regulating DR and TB. Recently, Ueno et al. reported that a tumor grading system based on
DR and TB provides more precise prediction of individual patients than the conventional staging [42]. In the present study, compared with patients with either one of MY or TB, those with both MY and TB developed postoperative relapse much more frequently. The presence of both MY and TB might have a synergistic effect rather than an additive effect for postoperative relapse.

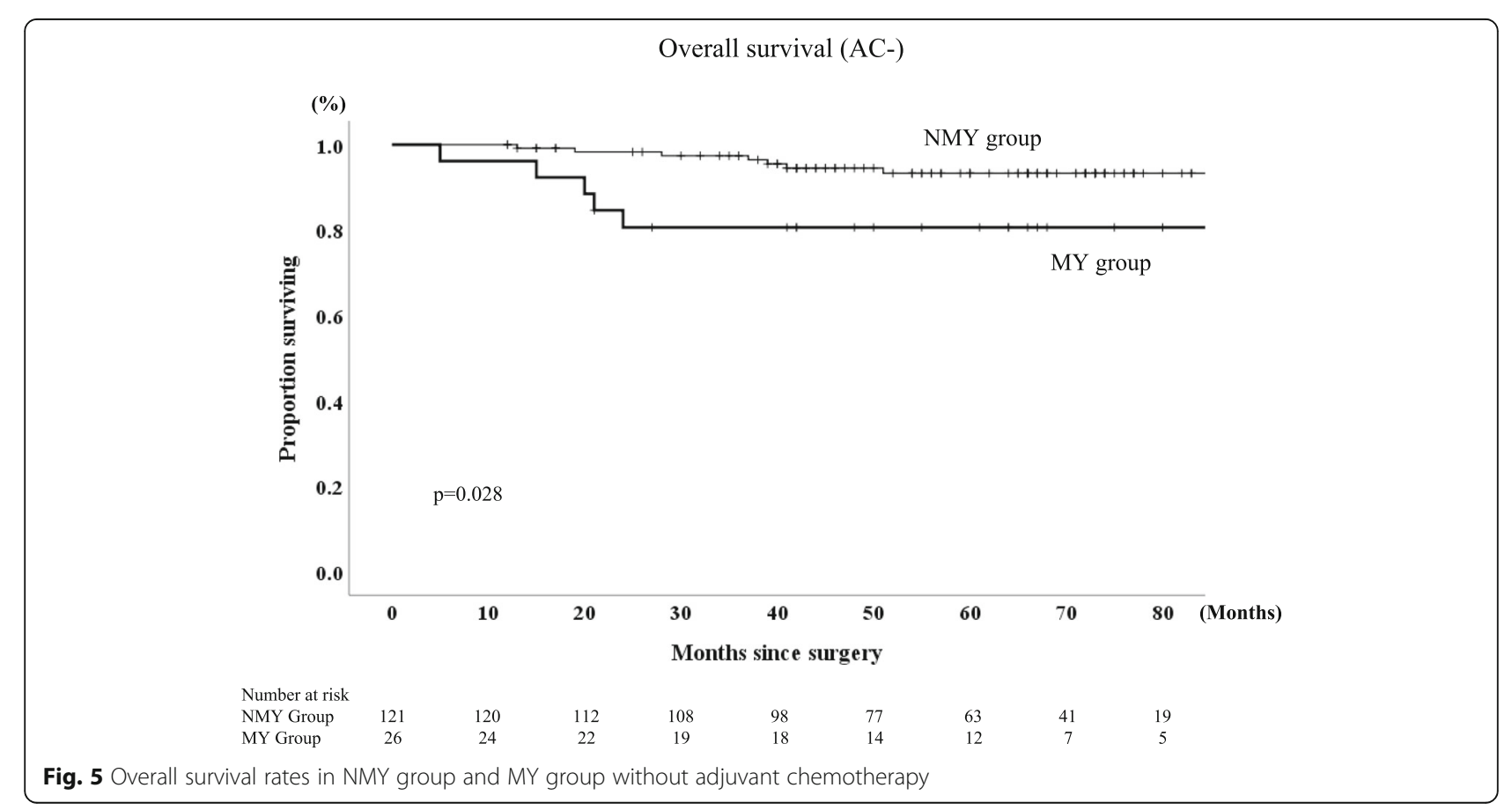


Table 4 Uni- and multi-variate analyses using Cox proportional hazard regression models to identify to Clinicopathological characteristics related to relapse free survival and overall survival

\begin{tabular}{|c|c|c|c|c|c|c|c|c|c|c|c|c|}
\hline \multirow{3}{*}{ Predictor } & \multicolumn{6}{|l|}{ RFS } & \multicolumn{6}{|l|}{ OS } \\
\hline & \multicolumn{3}{|c|}{ Univariate analysis } & \multicolumn{3}{|c|}{ Multivariate analysis } & \multicolumn{3}{|c|}{ Univariate analysis } & \multicolumn{3}{|c|}{ Multivariate analysis } \\
\hline & $\mathrm{HR}$ & $95 \% \mathrm{Cl}$ & $\boldsymbol{p}$ value & $\mathrm{HR}$ & $95 \% \mathrm{Cl}$ & $\boldsymbol{p}$ value & $\mathrm{HR}$ & $95 \% \mathrm{Cl}$ & $\boldsymbol{p}$ value & $\mathrm{HR}$ & $95 \% \mathrm{Cl}$ & $p$ value \\
\hline \multicolumn{13}{|l|}{ Gender } \\
\hline Male & 1 & & & & & & 1.00 & & & & & \\
\hline Female & 0.71 & $0.298-1.697$ & 0.44 & & & & 0.67 & $0.247-1.808$ & 0.43 & & & \\
\hline \multicolumn{13}{|l|}{ Age } \\
\hline$<70 \mathrm{yr}$ & 1 & & & & & & 1.00 & & & & & \\
\hline$\geq 70 \mathrm{yr}$ & 1.05 & $0.446-2.445$ & 0.92 & & & & 2.43 & $0.792-7.465$ & 0.12 & & & \\
\hline \multicolumn{13}{|l|}{ Serum CEA level } \\
\hline$<5$ & 1 & & & & & & 1.00 & & & & & \\
\hline$\geq 5$ & 1.41 & $0.609-3.264$ & 0.42 & & & & 0.91 & $0.337-2.465$ & 0.86 & & & \\
\hline \multicolumn{13}{|l|}{ Serum CA19-9 level } \\
\hline$<37.5$ & 1 & & & & & & 1.00 & & & 1 & & \\
\hline$\geq 37.5$ & 1.73 & $0.638-4.693$ & 0.28 & & & & 3.11 & $1.149-8.428$ & 0.026 & 0.62 & $0.355-1.096$ & 0.10 \\
\hline \multicolumn{13}{|l|}{ Tumor location } \\
\hline Right & 1 & & & & & & 1.00 & & & & & \\
\hline Left & 1.10 & $0.478-2.541$ & 0.82 & & & & 0.58 & $0.214-1.565$ & 0.28 & & & \\
\hline \multicolumn{13}{|l|}{ Differentiation } \\
\hline Well, moderately, pap & 1 & & & & & & 1.00 & & & & & \\
\hline por, muc & 0.36 & $0.049-2.698$ & 0.32 & & & & 1.18 & $0.268-5.198$ & 0.83 & & & \\
\hline \multicolumn{13}{|l|}{ Tumor size } \\
\hline$\leq 5$ & 1 & & & & & & 1.00 & & & & & \\
\hline$>5$ & 1.22 & $0.536-2.789$ & 0.63 & & & & 0.80 & $0.310-2.080$ & 0.65 & & & \\
\hline \multicolumn{13}{|l|}{ Tumor depth } \\
\hline pT3 & 1 & & & 1 & & & 1.00 & & & 1 & & \\
\hline pT4 & 2.52 & $0.986-6.452$ & 0.054 & 1.75 & $0.594-5.153$ & 0.31 & 3.66 & $1.352-9.922$ & 0.011 & 0.84 & $0.429-1.651$ & 0.62 \\
\hline \multicolumn{13}{|l|}{ Lymphatic invasion } \\
\hline Absent & 1 & & & & & & 1.00 & & & 1 & & \\
\hline Present & 1.03 & $0.398-2.264$ & 0.91 & & & & 2.48 & $0.941-6.515$ & 0.07 & 0.91 & $0.519-1.596$ & 0.74 \\
\hline \multicolumn{13}{|l|}{ Vessel invasion } \\
\hline Absent & 1 & & & & & & 1.00 & & & & & \\
\hline Present & 1.65 & $0.674-4.056$ & 0.27 & & & & 1.09 & $0.416-2.875$ & 0.86 & & & \\
\hline \multicolumn{13}{|l|}{ Tumor budding } \\
\hline Grade 1 & 1 & & & 1 & & & 1.00 & & & 1 & & \\
\hline Grade 2,3 & 9.00 & $3.042-26.624$ & $<0.001$ & 4.11 & $1.301-13.002$ & 0.02 & 6.18 & 2.015-18.977 & 0.001 & 1.94 & $1.020-3.668$ & 0.043 \\
\hline \multicolumn{13}{|l|}{ Surgical margin } \\
\hline Absent & 1 & & & 1 & & & 1.00 & & & 1 & & \\
\hline Present & 4.69 & $1.088-20.207$ & 0.038 & 4.33 & $0.769-24.343$ & 0.10 & 6.52 & $1.465-28.999$ & 0.014 & 0.56 & $0.219-1.411$ & 0.22 \\
\hline \multicolumn{13}{|l|}{ Lymph node yield } \\
\hline 12 or more & 1 & & & & & & 1.00 & & & & & \\
\hline Less than 12 & 1.03 & $0.420-2.524$ & 0.95 & & & & 1.10 & $3.87-3.131$ & 0.86 & & & \\
\hline \multicolumn{13}{|l|}{ Obstruction/perforation } \\
\hline Absent & 1 & & & & & & 1.00 & & & & & \\
\hline
\end{tabular}


Table 4 Uni- and multi-variate analyses using Cox proportional hazard regression models to identify to Clinicopathological characteristics related to relapse free survival and overall survival (Continued)

\begin{tabular}{|c|c|c|c|c|c|c|c|c|c|c|c|c|}
\hline \multirow{3}{*}{ Predictor } & \multicolumn{6}{|l|}{ RFS } & \multicolumn{6}{|l|}{ OS } \\
\hline & \multicolumn{3}{|c|}{ Univariate analysis } & \multicolumn{3}{|c|}{ Multivariate analysis } & \multicolumn{3}{|c|}{ Univariate analysis } & \multicolumn{3}{|c|}{ Multivariate analysis } \\
\hline & $\overline{\mathrm{HR}}$ & $95 \% \mathrm{Cl}$ & $\bar{p}$ value & $\overline{\mathrm{HR}}$ & $95 \% \mathrm{Cl}$ & $\bar{p}$ value & $\overline{\mathrm{HR}}$ & $95 \% \mathrm{Cl}$ & $\overline{p \text { value }}$ & $\overline{\mathrm{HR}}$ & $95 \% \mathrm{Cl}$ & $p$ value \\
\hline Present & 1.39 & $0.325-5.945$ & 0.66 & & & & 1.85 & $0.423-8.110$ & 0.41 & & & \\
\hline \multicolumn{13}{|l|}{ Operation } \\
\hline Laparotomy & 1 & & & & & & 1.00 & & & & & \\
\hline Laparoscopic surgery & 1.26 & $0.542-2.906$ & 0.60 & & & & 1.13 & $0.427-2.972$ & 0.81 & & & \\
\hline \multicolumn{13}{|l|}{ Glucose tolerance } \\
\hline Normal & 1 & & & & & & 1 & & & & & \\
\hline Abnormality & 1.88 & $0.636-5.556$ & 0.25 & & & & 1.92 & $0.550-6.677$ & 0.31 & & & \\
\hline \multicolumn{13}{|l|}{ Adjuvant chemotherapy } \\
\hline No & 1 & & & & & & 1 & & & & & \\
\hline Yes & 1.07 & $0.317-3.622$ & 0.91 & & & & 2.18 & $0.710-6.683$ & 0.17 & & & \\
\hline \multicolumn{13}{|l|}{ Myxoid stroma } \\
\hline Absent & 1 & & & 1 & & & 1 & & & 1 & & \\
\hline Present & 11.24 & $4.572-27.613$ & $<0.001$ & 6.80 & $2.579-17.911$ & $<0.001$ & 4.14 & $1.596-10.742$ & 0.003 & 0.66 & $0.371-1.157$ & 0.15 \\
\hline
\end{tabular}

Circulating CAFs (cCAFs) have recently been identified in the circulation, and metastasis-associated fibroblasts at the metastatic site promote the proliferation of cancer cells $[43,44]$. Cornil et al. reported that fibroblasts affected the proliferation of melanoma cells, and that only metastasized melanoma cells were influenced by fibroblasts [45]. Since MY has been closely associated with metastasis in previous reports [21, 29-32], specific stimuli released by MY may move cCAFs to metastatic sites. In fact, $65 \%$ of patients with MY developed tumor relapse, whereas only $12 \%$ of patients without MY did.

The present study has several limitations, such as its retrospective design and small sample size in a single institution. A difference in the relapse rate between patients with mature stroma and those with intermediate stroma might have been found if the sample size had been larger. In the present study, multivariate analysis did not show that MY was an independent risk factor for OS in patients with stage II colon cancer. This might have been due to the short follow-up and the effects of $\mathrm{AC}$ and treatment for relapse, such as surgical intervention and intensive chemotherapy. In addition, neither MSI nor MMR, which are considered to be predictive in the NCCN guideline, was examined, and the effect of $\mathrm{AC}$ according to the $\mathrm{NCCN}$ guideline was not examined.

Table 5 Analyses using Cox proportional hazard model for the combination myxoid stroma and tumor budding on relapse free survival and overall survival rates

\begin{tabular}{|c|c|c|c|c|c|c|c|c|c|}
\hline Combinations & $\begin{array}{l}\text { Number of relapse } \\
(\%)\end{array}$ & $\begin{array}{l}\text { 5-year RFS rate } \\
\text { (\%) }\end{array}$ & $\mathrm{HR}$ & $95 \% \mathrm{Cl}$ & $p$ value & $\begin{array}{l}\text { 5-year OS rate } \\
(\%)\end{array}$ & $\mathrm{HR}$ & $95 \% \mathrm{Cl}$ & $\begin{array}{l}p \\
\text { value }\end{array}$ \\
\hline MY- / TB - & 4/99 (4) & 96.7 & 1 & & & 97.9 & 1 & & \\
\hline $\mathrm{MY}-/ \mathrm{TB}+$ & 4/37 (10.8) & 88.1 & 4.003 & $\begin{array}{l}0.896- \\
17.896\end{array}$ & 0.069 & 85.2 & 8.75 & $\begin{array}{l}1.766- \\
43.360\end{array}$ & 0.008 \\
\hline $\mathrm{MY}+/ \mathrm{TB}-$ & $1 / 7(14.3)$ & 85.7 & 4.798 & $\begin{array}{l}0.499- \\
46.134\end{array}$ & 0.174 & 71.4 & 12.95 & $\begin{array}{l}1.815- \\
92.432\end{array}$ & 0.011 \\
\hline $\mathrm{MY}+/ \mathrm{TB}+$ & $14 / 26(53.8)$ & 44.2 & 24.42 & $\begin{array}{l}6.992- \\
85.255\end{array}$ & $\begin{array}{l}< \\
0.001\end{array}$ & 72.5 & 15.64 & $\begin{array}{l}3.245- \\
75.337\end{array}$ & 0.001 \\
\hline $\begin{array}{l}\mathrm{MY}+\text { / TB- or MY- / } \\
\mathrm{TB}+\end{array}$ & $5 / 44(11.4)$ & 87.7 & 1 & & & 82.1 & 1 & & \\
\hline $\mathrm{MY}+/ \mathrm{TB}+$ & $14 / 26(53.8)$ & 44.2 & 5.801 & $\begin{array}{l}2.084- \\
16.146\end{array}$ & 0.001 & 72.5 & 1.619 & $0.596-4.562$ & 0.335 \\
\hline
\end{tabular}


In conclusion, the present results suggest that MY is a useful predictive feature for postoperative relapse in patients with stage II colon cancer. Although the additional larger trials should be added, if both MY and TB are identified in the lesion, the risk of tumor relapse may be a high. Since MY may become a useful information for deciding whether to add $\mathrm{AC}$ in patients with stage II colon cancer, it should be confirmed in multiinstitutional trials for a large number of patients.

\section{Abbreviations}

AC: Adjuvant chemotherapy; CAF: Cancer-associated fibroblast; CAPE: Capecitabin; CAPEOX: CAPE plus oxaliplatin; DR: Desmoplastic reaction; FOLFOX: Fluorouracil, leucovorin plus oxaliplatin; MA: Mature stroma; ECM: Extracellular matrix; IN: Intermediate stroma; MSI: Microsatellite instability; MMR: Mismatch repair; MY: Myxoid stroma; NCCN: National Comprehensive Cancer Network; NMY: Non-myxoid stroma; UFT/

LV: Fluorouracil plus leucovorin; OS: Overall survival; RFS: Relapse-free survival; TB: Tumor budding

\section{Acknowledgements}

Not applicable.

\section{Authors' contributions}

TO participate in the design of this study, the surgical procedures, and the data analysis. SS, ET, TM, TN, NT, and MO participated in the surgical procedures. YO, SB, TO participated in the pathological diagnosis. All authors read and approved the final manuscript.

\section{Funding}

Not applicable.

\section{Availability of data and materials}

The datasets used and/or analyzed during the current study are available from the corresponding author on reasonable request.

\section{Ethics approval and consent to participate}

This study was approved by the Ethics Committee of Saitama Medical Center, Dokkyo Medical University (No. 1762). All participants were provided written informed consent in the study.

\section{Consent for publication}

Not applicable.

\section{Competing interests}

The authors declare that they have no competing interests.

\section{Author details}

${ }^{1}$ Department of Surgery, Saitama Medical Center, Dokkyo Medical University, 干 343-8555 2-1-50 Minami-Koshigaya, Koshigaya, Saitama, Japan. ${ }^{2}$ Department of Pathology, Saitama Medical Center, Dokkyo Medical University, Saitama, Japan.

Received: 28 December 2019 Accepted: 24 August 2020

Published online: 03 September 2020

\section{References}

1. O'Connor ES, Greenblatt DY, LoConte NK, et al. Adjuvant chemotherapy for stage II colon cancer with poor prognostic features. J Clin Oncol. 2011;29: 3381-8.

2. Si Q, Andre T, Grother A, et al. Comparison of outcomes after fluorouracilbased adjuvant therapy for stage II and III colon cancer between 1978 to 1995 and 1996 to 2007: Evidence of stage migration from the ACCENT database. J Clin Oncol. 2013;31:3656-63.

3. Weiss JM, Schumacher J, Allen GO, et al. Adjuvant chemotherapy for stage II right- and left-side colon cancer: analysis of SEER-Medicare data. Ann Surg Oncol. 2014;21:1781-91.
4. Casadaban L, Rauscher G, Aklilu M, Villenes D, Freels S, Maker AV. Adjuvant chemotherapy is associated with improved survival in patients with stage II colon cancer. Cancer. 2016;122:3277-87.

5. Gunderson LL, Jessuq JM, Sarqent DJ, Greene FL, Stewart AK. Revised TN categorization for colon cancer based on national survival outcomes data. J Clin Oncol. 2010;28:264-71.

6. NCCN Clinical practice guidelines in oncology: Colon Cancer, National Comprehensive Cancer Network Colon Cancer (version 1). 2019. http:// www.nccn.org/professionals/physician_gls/PDF/colon.pdf. Accessed 7 Apr 2019.

7. Benson AB 3rd, Schrag D, Somerfield MR, Cohen AM, Fiqueredo AT, Flynn PJ, et al. American Society of Clinical Oncology recommendations on adjuvant chemotherapy for stage II colon cancer. J Clin Oncol. 2004;22: 3408-19.

8. Labianca R, Nordlinger B, Beretta GD, Mosconi S, Mandala M, Cervantes A et al. ESMO Guidelines Working Group. Early colon cancer: ESMO Clinical Practice Guidelines for diagnosis, treatment and follow-up. Ann Oncol. 2013; 24(suppl 6):vi64-72.

9. Bertabnolli MM, Redston M, Compton CC, Niedzwiecki D, Mayer RJ, Goldberg RM, et al. Microsatellite instability and loss of heterozygosity at chromosomal location 18q: prospective evaluation of biomarkers for stage II and III colon cancer - a study of CALGB 9581 and 89803. J Clin Oncol. 2011; 29:3153-62.

10. Gavin PG, Colangelo LH, Fumagahan TS, et al. Mutation profiling and microsatellite instability in stage II and III colon cancer: an assessment of their prognostic and Oxaliplatin predictive value. Clin Cancer Res. 2012;18: 6531-41.

11. Zhang JX, Song W, Chen ZH, et al. Prognostic and predictive value of a microRNA signature in stage $\|$ colon cancer: a microRNA expression analysis. Lancet Oncol. 2013;14:1295-306.

12. Dalerba $P$, Sahoo D, Paik $S$, et al. CDX2 as a prognostic biomarker in stage II and stage III colon cancer. N Engl J Med. 2016:374:211-22.

13. Wiseman BS, Werb Z. Stromal effects on mammary gland development and breast cancer. Science. 2002;296:1046-9.

14. Kalluri R. Basement membranes: structure, assembly and role in tumor angiogenesis. Nat Rev Cancer. 2003;3:422-33.

15. Karagiannis GS, Poutahidis T, Erdman SE, Kirsch R, Riddell RH, Diamandis EP. Cancer-associated fibroblasts drive the progression of metastasis through both paracrine and mechanical pressure on cancer tissue. Mol Cancer Res. 2012;10:1403-18.

16. Ishii G, Ochiai A, Neri S. Phenotype and functional heterogeneity of cancerassociated fibroblast within the tumor microenvironment. Adv Drug Deliv Rev. 2015;99:186-96.

17. Kalluri R, Zeisberq M. Fibroblasts in Cancer. Nat Rev Cancer. 2006;6:392-401.

18. Komohara Y, Takeya M. CAFs and TAMs: maestros of the tumor microenvironment. J Pathol. 2017;241:313-5.

19. Hewitt RE, Powe DG, Carter Gl, Turner DR. Desmoplasia and its relevance to colorectal tumour invasion. Int J Cancer. 1993;53:62-9.

20. van Kempen LC, Ruiter DJ, van Muijen GN, Coussens LM. The tumor microenvironment: a critical determinant of neoplastic evolution. Eur J Cell Biol. 2003:82:539-48.

21. Watt J, Kocher HM. The desmoplastic stroma of pancreatic cancer is a barrier to immune cell infiltration. Oncoimmunology. 2013;2:e26788.

22. Ueno H, Shinto E, Shimazaki H, Kajiwara Y, Sueyama T, Yamamoto J, et al. Histologic categorization of desmoplastic reaction: its relevance to the colorectal cancer microenvironment and prognosis. Ann Surg Oncol. 2015; 22:1504-12.

23. Lao XM, Liang YJ, Su YX, Zhang SE, Zhou X, Lioa GQ. Distribution and significance of intestinal fibrosis and stroma-infiltrating $B$ cells in tongue squamous cell carcinoma. Oncol Lett. 2016;11:2027-34.

24. American Joint Committee on Cancer (AJCC), Aim MB, Edge SB, Greene FL, Byrd DR, Brookland RK, Washington MK, et al. Cancer Staging Manual. 8th ed. New York: Springer; 2017

25. Ueno $\mathrm{H}$, Jones AM, Wilkinson $\mathrm{KH}$, Jass JR, Talbot IC. Histological categorization of fibrotic cancer stroma in advanced rectal cancer. Gut. 2004:53:581-6.

26. Ueno H, Murphy J, Jass JR, Mochizuki H, Talbot I. Tumor "budding" as an index to estimate the potential of aggressiveness in rectal cancer. Histopathology. 2002:40:127-32.

27. Lugli A, Kirsch R, Ajioka Y, Bosman F, Cathomas G, Dawson H, et al. Recommendations for reporting tumor budding in colorectal cancer base 
on the international tumor budding consensus conference (ITBCC) 2016. Mod Pathol. 2017;30:1299-311.

28. Watanabe T, Muro K, Ajioka Y, Hashiguchi Y, Ito Y, Saito Y, et al. Japanese society for cancer of the colon and rectum (JSCCR) guideline 2016 for the treatment of colorectal cancer. Int J Clin Oncol. 2018;23:1-34.

29. Hemandez-Ruiz E, Hemandez-Munoz I, Masferrer E, Ferrandiz-Pulido C, Andrades $\mathrm{E}$, Gimeno J, et al. A myxoid fibrotic reaction pattern is associated with metastatic risk in cutaneous squamous cell carcinoma. Acta Derm Venereol. 2019;99:89-94.

30. Laqace R, Grimaud JA, Schurch W, Seemayer TA. Myofibroblastic stromal reaction in carcinoma of the breast: variations of collagenous matrix and structural glycoproteins. Virchows Arch A Pathol Anat Histopathol. 1985;408: 49-59.

31. Nakanishi H, Oquri K, Takenaga K, Hosoda S, Okayama M. Differential fibrotic stromal responses of host tissue to low- and high-metastatic cloned Lewis lung carcinoma cells. Lab Investig. 1994;70:324-32.

32. Ueno $\mathrm{H}$, Jones $\mathrm{A}$, Jass JR, Talbot IC. Clinicopathological significance of the 'keloid-like' collagen and myxoid stroma in advanced rectal cancer. Histopathology. 2002;40:327-34.

33. Jass JR, Atkin WS, Cuzick J, Bussey HJR, Morson BC, Northover JMA, et al. The grading of rectal cancer: histological perspectives and a multivariate analysis of 447 cases. Histopathology. 1986;10:437-59.

34. Leon MP, Sant M, Micheli A, Sacchetti C, Greqorio CD, Fante R, et al. Clinical and pathologic prognostic indicators in colorectal cancer. Cancer. 1992;69: 626-35.

35. Markowitz SD, Bertagnolli MM. Molecular origins of cancer: molecular basis of colorectal cancer. N Engl J Med. 2009;361:2449-60.

36. Giardiello FM, Brensinger JD, Petersen GM. AGA technical review on hereditary colorectal cancer and genetic testing. Gastroenterology. 2001; 121:198-213.

37. Sarquent DJ, Marsoni S, Monqes G, Thiboseau SN, Labianca R, Hamilton SR, et al. Defective mismatch repair as a predictive marker for lack of efficacy of fluorouracil-based adjuvant therapy in colon cancer. J Clin Oncol. 2010;28: 3219-26.

38. Hutchins G, Southward K, Handley K, et al. Value of mismatch repair, KRAS, and BRAF mutations in predicting recurrence and benefits from chemotherapy in colorectal cancer. J Clin Oncol. 2011:29:1261-70.

39. Ribic CM, Sargent DJ, Moore MJ, Thibodeau SN, French AJ, Goldberg RM, et al. Tumor microsatellite-instability status as a predictor of benefit from fluorouracil-based adjuvant chemotherapy for colon cancer. N Engl J Med. 2003;349:247-57.

40. Mueller MM, Fusenig NE. Friends of foes - bipolar effects of the tumor stroma in cancer. Nature Rev Cancer. 2004;4:839-49.

41. Paolillo M, Schinelli S. Extracellular matrix alterations in metastatic processes. Int J Mol Sci. 2019;20:4947.

42. Ueno H, Shinto E, Kajiwara Y, Fukazawa S, Shimazaki H, Yamamoto J, et al. Prognostic impact of histological categorization of epithelial-mesenchymal transition in colorectal cancer. Br J Cancer. 2014:111:2082-90.

43. Duda DG, Duyverman AM, Kohno M, Snuderl M, Steller EJ, Jain RK, et al. Malignant cells facilitate lung metastasis by bringing their own soil. Proc Natl Acad USA. 2010;107:21677-82.

44. Zheng A, Shah SH, Machlin LM, Parajuli R, Miller PC, Rawal S, et al. Identification of cancer-associated fibroblasts in circulating blood from patients with metastatic breast cancer. Cancer Res. 2015;75:4681-7.

45. Cornil I, Theodorescu D, Man S, Herlyn M, Jambrosic J, Kerbel RS. Fibroblast cell interactions with human melanoma cells affect tumor cell growth as a function of tumor progression. Proc Natl Acad Sci U S A. 1991;88:6028-32.

\section{Publisher's Note}

Springer Nature remains neutral with regard to jurisdictional claims in published maps and institutional affiliations.

\section{Ready to submit your research? Choose BMC and benefit from:}

- fast, convenient online submission

- thorough peer review by experienced researchers in your field

- rapid publication on acceptance

- support for research data, including large and complex data types

- gold Open Access which fosters wider collaboration and increased citations

- maximum visibility for your research: over $100 \mathrm{M}$ website views per year

At BMC, research is always in progress.

Learn more biomedcentral.com/submissions 